\title{
Bidirectional effects of dexmedetomidine on human platelet functions in vitro.
}

AUTHOR(S):

Kawamoto, Shuji; Hirakata, Hideo; Sugita, Naoko; Fukuda, Kazuhiko

\section{CITATION:}

Kawamoto, Shuji ... [et al]. Bidirectional effects of dexmedetomidine on human platelet functions in vitro.. European journal of pharmacology 2015, 766: 122-128

\section{ISSUE DATE:}

2015-11-05

URL:

http://hdl.handle.net/2433/207650

\section{RIGHT:}

(c) 2015. This manuscript version is made available under the CC-BY-NC-ND 4.0 license

http://creativecommons.org/licenses/by-nc-nd/4.0/; The full-text file will be made open to the public on 5 December 2016 in accordance with publisher's 'Terms and Conditions for Self-Archiving'.; この論文は出版社版でありません。引 用の際には出版社版をご硫認ご利用ください。; This is not the published version. Please cite only the published version. 
Bidirectional effects of dexmedetomidine on human platelet functions in vitro

Shuji Kawamoto ${ }^{\mathrm{a}, *}$, Hideo Hirakata ${ }^{\mathrm{b}}$, Naoko Sugita $^{\mathrm{c}}$, Kazuhiko Fukuda $^{\mathrm{a}}$

Departments of ${ }^{\mathrm{a}}$ Anesthesia and ${ }^{\mathrm{c}}$ Psychiatry, Kyoto University Hospital, 54 Shogoin Kawaharacho, Sakyo-ku, Kyoto 606-8507, Japan

${ }^{\mathrm{b}}$ Department of Anesthesia, National Hospital Organization Kyoto Medical Center, 1-1

Fukakusa mukaihata-cho, Fushimi-ku, Kyoto 612-8555, Japan

*Corresponding Author.

E-mail address: shuji-kawamoto@ares.eonet.ne.jp (S. Kawamoto) 


\section{ABSTRACT}

Platelets express the imidazoline (I)-receptor, $\mathrm{I}_{1}$ and $\mathrm{I}_{2}$, as well as the $\alpha_{2}$-adrenoceptor. Although dexmedetomidine, a selective $\alpha_{2}$-adrenoceptor agonist with some affinity for the I-receptor is expected to affect platelet function, the effects of dexmedetomidine on platelet functions remain unclear. In the present study, we investigated the effects of dexmedetomidine on human platelet functions in vitro. The effects of dexmedetomidine on platelet aggregation were examined using aggregometers. The formation of cyclic adenosine monophosphate (cAMP) and cyclic guanosine monophosphate (cGMP) in platelets was measured by an enzyme immunoassay. In addition, Pselectin expression in platelets was estimated by flow cytometry. Dexmedetomidine enhanced and suppressed platelet aggregation in the absence and the presence of yohimbine, an $\alpha_{2}-$ antagonist, respectively. Efaroxan, an $\mathrm{I}_{1}$-antagonist, and methylene blue, a soluble guanylate cyclase inhibitor, abolished the suppressive effect of dexmedetomidine, whereas idazoxan, an $\mathrm{I}_{2}{ }^{-}$ antagonist, showed no effect. Dexmedetomidine suppressed cAMP formation and enhanced Pselectin expression in platelets, and these effects were inhibited by yohimbine.

Dexmedetomidine increased cGMP formation in platelets in the presence of yohimbine, and this increase was suppressed by efaroxan. These results demonstrated that dexmedetomidine has both enhancing and suppressive effects on human platelet functions through its action on the $\alpha_{2}-$ adrenoceptor and on the $\mathrm{I}_{1}$-receptor, respectively.

Key Words: Dexmedetomidine, Platelet, $\alpha_{2}$-adrenoceptor, Imidazoline receptor 


\section{Introduction}

Because platelets are essential for maintaining hemostasis, information on the effects of perioperatively used drugs including anaesthetics on platelet functions is indispensable for patient care. Previously, the inhibitory effects of volatile anaesthetics on human platelet aggregation were shown in both in vitro (Hirakata et al., 1995; Hirakata et al., 1996) and in vivo studies (Hirakata et al., 1997). With respect to intravenous anaesthetics, we have reported that propofol has both enhancing and suppressive effects on human platelet aggregation in vitro (Hirakata et al., 1999), and ketamine inhibits human platelet aggregation possibly by suppression of inositol trisphosphate formation (Nakagawa et al., 2002). However, the effects of a number of drugs, which have recently become clinically applicable, on platelet functions remain to be examined.

It has not been extencively examined whether dexmedetomidine, an R (+)-enantiomer of medetomidine with a highly selective affinity for the $\alpha_{2}$-adrenoceptor, that is clinically used for sedation and analgesia (Kamibayashi and Maze, 2000; Ramsay and Luterman, 2004), affects human platelet function. As it was reported that adrenaline can potentiate platelet aggregation by activation of the $\alpha_{2}$-adrenoceptor in platelets (Lanza and Cazenave, 1985), it is probable that dexmedetomidine also affects platelet functions. Dexmedetomidine also exhibits some affinity for imidazoline (I)-receptors, which are expressed in various cells, including platelets, and are suggested to participate in many physiological functions (Dahmani et al., 2008; Ernsberger et al., 1997a; Ernsberger and Haxhiu, 1997b; Savola and Savola, 1996; Virtanen et al., 1988; Wikberg 
et al., 1991). The existence of $\mathrm{I}_{1}$ - and $\mathrm{I}_{2}$-receptors in human platelets (Michel et al., 1990; Piletz and Sletten, 1993; Piletz et al., 1996), and the suppressive effect of imidazoline agents on rabbit platelet aggregation via I-receptors (Yokota et al., 2013), may suggest that dexmedetomidine can affect human platelet functions via I-receptors. It is important clinically as well as pharmacologically to examine the effect of dexmedetomidine on platelet functions, because dexmedetomidine is often administered to critically ill patients whose platelet number in the blood is seriously decreased by a variety of pathophysiological mechanisms,.

The aim of this study was to evaluate the effects of dexmedetomidine on human platelet functions and to elucidate the underlying mechanisms especially concerning the $\alpha_{2}$ adrenoreceptor and I-receptors. Our results demonstrate that dexmedetomidine has both enhancing and suppressive effects on human platelet functions through action on the $\alpha_{2}$ adrenoceptor and the $\mathrm{I}_{1}$-receptor, respectively. 


\section{Materials and methods}

\subsection{Platelet preparation}

Written informed consent was obtained from subjects, and the protocol was approved by the ethics committee of Kyoto University Hospital. Venous blood was obtained by venipuncture of antecubital veins from 15 healthy volunteers who had not taken any medication for at least two weeks before blood sampling. The blood was mixed with $10 \%$ volume of $3.8 \%$ tri-sodium citrate. Platelet-rich plasma (PRP) was prepared by centrifugation of the blood sample at $160 \mathrm{~g}$ for $10 \mathrm{~min}$ at room temperature and collection of the supernatant. The remaining lower portion was further centrifuged at $1600 \mathrm{~g}$ for $30 \mathrm{~min}$ at room temperature, and the clear supernatant was used as platelet-poor plasma (PPP).

\subsection{Chemicals and drugs}

Dexmedetomidine and idazoxan were purchased from Santa Cruz Biotechnology (Santa Cruz, CA, USA). Yohimbine and methylene blue were purchased from Nacalai Tesque (Kyoto, Japan). Levomedetomidine, an S (-)-enantiomer of medetomidine was kindly supplied by Orion Corporation (Espoo, Finland). Adenosine diphosphate (ADP) and efaroxan were purchased from Sigma-Aldrich (St. Louis, MO, USA), and Tocris Bioscience (Bristol, UK), respectively. 9, 11epithio-11, 12-methanothromboxane $\mathrm{A}_{2}\left(\mathrm{STA}_{2}\right)$ was provided by Ono Pharmaceutical (Osaka, Japan). Peridinin Chlorophyll Protein (PerCP)-labeled anti-CD61 antibody, Phycoerythrin (PE)labeled anti-CD62P (P-selectin) antibody and PE-labeled IgG for control were obtained from 
Becton Dickinson (San Diego, CA, USA). All other chemicals were of analytical grade. We confirmed that all buffers or solvents for diluting materials in our experiments showed no effect on the results.

\subsection{Measurement of agonist-induced and spontaneous platelet aggregation}

An aliquot of PRP was pipetted into a cylindrical cuvette containing either dexmedetomidine or levomedetomidine and incubated at $37^{\circ} \mathrm{C}$ for $3 \mathrm{~min}$ in the presence or absence of various antagonists (yohimbine, efaroxan, idazoxan and methylene blue). Then, the sample was stirred constantly at $37^{\circ} \mathrm{C}$ with a magnetic bar at a rate of $1000 \mathrm{rpm}$. ADP-induced aggregation was measured for 7 min as a change in light transmission using an aggregometer (MCM Hema Tracer 212; MC Medical, Tokyo, Japan). The light transmission of PPP was taken as $100 \%$, and aggregation was expressed as percentage of the light transmission. Spontaneous platelet aggregation in PRP was measured without any agonists for 7 min using an ultra-sensitive platelet aggregation analyzer (PA-200, Kowa, Tokyo, Japan), and expressed as light scattering intensity.

\subsection{Cyclic adenosine monophosphate (cAMP) and cyclic guanosine monophosphate (cGMP)} assays

Washed platelets were used in in cAMP and cGMP assays to exclude the possible effects of other blood cells on the results. PRP in a $10 \%$ volume of $100 \mathrm{mM}$ ethylenediaminetetraacetic acid 
(EDTA) was centrifuged at $900 \mathrm{~g}$ for $15 \mathrm{~min}$ at $4^{\circ} \mathrm{C}$. The pellet was suspended in the wash buffer containing $8 \mathrm{mM} \mathrm{Na}_{2} \mathrm{HPO}_{4}, 2 \mathrm{mM} \mathrm{NaH} \mathrm{PO}_{4}, 10 \mathrm{mM}$ EDTA, $135 \mathrm{mM} \mathrm{NaCl}$ and $5 \mathrm{mM} \mathrm{KCl}$, and centrifuged again at $900 \mathrm{~g}$ for $15 \mathrm{~min}$ at $4^{\circ} \mathrm{C}$. The platelets were finally suspended at a concentration of either $10^{6}$ platelets $\mu 1^{-1}$ or $2.5 \times 10^{6}$ platelets $\mu 1^{-1}$ for the cAMP and cGMP assays, respectively, in the assay buffer containing $10 \mathrm{mM} \mathrm{N}$-2-Hydroxyethylpiperazine-N'-2'ethanesulfonic acid (HEPES), $0.5 \mathrm{mM} \mathrm{Na}_{2} \mathrm{HPO}_{4}, 145 \mathrm{mM} \mathrm{NaCl}, 5 \mathrm{mM} \mathrm{KCl}$, and $6 \mathrm{mM}$ glucose.

For the cAMP assay, $100 \mu \mathrm{l}$ of the platelet suspension was incubated at $37^{\circ} \mathrm{C}$ for $3 \mathrm{~min}$ in a cylindrical cuvette, and then stirred with a magnetic bar at a rate of $1,000 \mathrm{rpm}$ at $37^{\circ} \mathrm{C}$. Platelets were stimulated with $0.1 \mu \mathrm{M} \mathrm{STA}$, a stable thromboxane $\mathrm{A}_{2}$ analog, at $37^{\circ} \mathrm{C}$ for $7 \mathrm{~min}$ in the presence or absence of either dexmedetomidine or levomedetomidine with or without yohimbine. $\mathrm{STA}_{2}$ was used for stimulation in this experiment, because washed platelets cannot be activated by ADP. For the cGMP assay, $100 \mu$ of the platelet suspension containing yohimbine was incubated at $37^{\circ} \mathrm{C}$ for $3 \mathrm{~min}$ in a cylindrical cuvette in the presence or absence of either dexmedetomidine or rilmenigine with or without efaroxan, and then stirred with a magnetic bar at a rate of $1,000 \mathrm{rpm}$ at $37^{\circ} \mathrm{C}$ for $7 \mathrm{~min}$. In both the cAMP and cGMP assays, the reaction was terminated by adding $10 \%$ volume of $0.1 \mathrm{M}$ ice-cold $\mathrm{HCl}$, and the samples were kept at $-20^{\circ} \mathrm{C}$ until measurement.

The cAMP and cGMP measurements were performed using commercially available enzyme immunoassay kits (Cyclic AMP EIA Kit No. 581001 and Cyclic GMP EIA Kit No. 581021 Cayman Chemical, Michigan, USA), according to the manufacturer's protocol. 


\subsection{Flow cytometry analysis for P-selectin expression on ADP-stimulated and unstimulated} platelets

PRP was diluted 10-fold with phosphate-buffered saline (PBS) containing $139 \mathrm{mM} \mathrm{NaCl}$, $8.1 \mathrm{mM} \mathrm{NaHPO}_{4}, 1.5 \mathrm{mM} \mathrm{KH}_{2} \mathrm{PO}_{4}$, and $2.7 \mathrm{mM} \mathrm{KCl}$. For the ADP-stimulated platelet analysis, an aliquot of diluted PRP was incubated with either dexmedetomidine or levomedetomidine in the presence or absence of yohimbine at room temperature for $30 \mathrm{~min}$. Some samples were coincubated with ADP. For the analysis of unstimulated platelets, an aliquot of diluted PRP was pipetted into a cylindrical cuvette and incubated at $37^{\circ} \mathrm{C}$ for $3 \mathrm{~min}$ with either dexmedetomidine or levomedetomidine in the presence or absence of yohimbine. Then, the samples were stirred constantly with a magnetic bar at a rate of $1,000 \mathrm{rpm}$ at $37^{\circ} \mathrm{C}$ for $7 \mathrm{~min}$ and incubated at room temperature for $30 \mathrm{~min}$ without stirring. In both assays, samples were fixed with ice-cold $1 \%$ formaldehyde for 60 min on ice and washed twice with ice-cold PBS by centrifugation at $900 \mathrm{~g}$ for $15 \mathrm{~min}$ at $4^{\circ} \mathrm{C}$. The pellet was suspended in $100 \mu \mathrm{PBS}$ at $4^{\circ} \mathrm{C}$. Then, $5 \mu \mathrm{l}$ of the platelet suspension was co-incubated with PerCP-labeled anti-CD61 antibody and PE-labeled antiCD62P (P-selectin) antibody in a final volume of $50 \mu$ adjusted with PBS for 60 min at room temperature in the dark. PE-labeled IgG was used to estimate the nonspecific binding. The reaction was stopped by adding ice-cold PBS. Samples were analyzed using a fluorescenceactivated cell sorting (FACS) Calibur instrument (Becton Dickinson, San Jose, CA, USA). For each sample, data from 10,000 platelets were collected. Platelets were identified by forward and side scatter intensity and by CD61 expression. P-selectin expression levels on activated platelet surface membranes were recorded as the mean fluorescent intensity (MFI) of PE. 


\subsection{Statistical Analysis}

All data are expressed as mean \pm standard deviation $(\mathrm{SD})$ of three to five sepatate experiments. The group variances were tested by the Brown-Forsythe test, and statistically equal. All data were compared with one-way analysis of variance (ANOVA), followed by the Dunnett's test. Statistical analyses were performed using Prism 5.0 software (GraphPad Software, San Diego, CA, USA). $P$ values less than 0.05 were considered to indicate statistical significance. 


\section{Results}

\subsection{Effects of dexmedetomidine on platelet aggregation}

Dexmedetomidine (10-500 $\mathrm{ng} \mathrm{ml}^{-1}$ ) enhanced platelet aggregation induced by $0.5 \mu \mathrm{M}$ ADP in a dose-dependent manner, while levomedetomidine (500 $\left.\mathrm{ng} \mathrm{ml}^{-1}\right)$, an $\mathrm{S}(-)$-enantiomer of medetomidine with an $\alpha_{2}$-adrenoceptor binding affinity much lower than that of dexmedetomidine (Jansson et al., 1994), had no significant effect (Fig. 1A). We next aimed to pharmacologically analyze which receptor is involved in the effect of dexmedetomidine on platelet aggregation. We used 1.5 $\mu \mathrm{M}$ ADP for stimulation in this experiment, because platelet aggregation induced by $0.5 \mu \mathrm{M}$ ADP was too low to examine the effect of antagonists on the enhancing effect. Yohimbine alone did not affect ADP-induced platelet aggregation (data not shown). Fig. 1B shows that the enhancing effect of dexmedetomidine on platelet aggregation was abolished by yohimbine, suggesting that dexmedetomidine activates platelet aggregation through the activation of the $\alpha_{2}$-adrenoceptor in the presence of ADP stimulation. Interestingly, platelet aggregation in the presence of dexmedetomidine and yohimbine was significantly lower than that of the control level, indicating that dexmedetomidine has a suppressive effect on platelet aggregation by a mechanism other than through the $\alpha_{2}$-adrenoceptor. Efaroxan, an $\mathrm{I}_{1}$ antagonist, abolished the suppressive effect of dexmedetomidine in the presence of yohimbine, but idazoxan, an $\mathrm{I}_{2}$-antagonist, did not (Fig. 1B). This result suggests that dexmedetomidine suppresses platelet aggregation via the $\mathrm{I}_{1}$-receptor. Methylene blue, a soluble guanylate cyclase (GC) inhibitor, was used to examine whether dexmedetomidine suppresses platelet aggregation by activation of GC. Methylene blue alone did not affect ADP-induced platelet aggregation (data 
not shown), but abolished the suppressive effect of dexmedetomidine on ADP-induced platelet aggregation in the presence of yohimbine (Fig. 1B), indicating that GC activation mediates the suppressive effect of dexmedetomidine.

We next examined whether dexmedetomidine affects platelet aggregation in the absence of stimulation. Fig. 1C demonstrates that dexmedetomidine $\left(10 \mathrm{ng} \mathrm{ml}^{-1}\right)$ enhanced spontaneous platelet aggregation, while levomedetomidine $\left(100 \mathrm{ng} \mathrm{ml}^{-1}\right)$ had no significant effect. Furthermore, the enhancing effect of dexmedetomidine was suppressed by yohimbine. Thus, our results show that dexmedetomidine activates platelet aggregation through activation of the $\alpha_{2}$ adrenoceptor regardless of the presence or absence of ADP stimulation.

\subsection{Mechanism of $\alpha_{2}$-adrenoceptor-mediated platelet activation}

It is well known that a decrease in the cAMP levels plays a major role in the plateletactivating effects of the $\alpha_{2}$-adrenoceptor (Keularts et al., 2000). Fig. 2A shows that dexmedetomidine (10 $\mathrm{ng} \mathrm{ml}^{-1}$ ) suppressed cAMP formation, and this effect of dexmedetomidine was blocked by yohimbine. Levomedetomidine $\left(100 \mathrm{ng} \mathrm{ml}^{-1}\right)$ did not significantly affect cAMP formation with or without yohimbine (Fig. 2B). These results indicate that dexmedetomidine suppresses cAMP formation via the $\alpha_{2}$-adrenoceptor, which probably results in the enhancement of platelet aggregation.

Next, we assessed P-selectin expression to analyze the effect of dexmedetomidine on platelet functions other than platelet aggregation, because P-selectin expression increases on the 
surface of activated platelets in the process of granule secretion (Furie et al., 2001). Fig. 3 shows that dexmedetomidine (10-100 $\mathrm{ng} \mathrm{ml}^{-1}$ ) enhanced P-selectin expression on both ADP-stimulated and non-stimulated platelet surfaces in a dose-dependent manner, and the enhancing effect was abolished by yohimbine. Levomedetomidine (up to $100 \mathrm{ng} \mathrm{ml}^{-1}$ ) did not significantly affect surface P-selectin expression (Fig. 3). This result indicates that dexmedetomidine not only enhances platelet aggregation but also increases P-selectin expression via the $\alpha_{2}$-adrenoceptor in the presence or absence of ADP stimulation.

\subsection{Mechanism of $I_{1}$-receptor-mediated inhibition of platelet aggregation}

To elucidate the mechanism for the GC activation involved in the dexmedetomidineinduced inhibition of platelet aggregation mediated by the $\mathrm{I}_{1}$-receptor (see above), we tested whether cGMP is increased by dexmedetomidine. Fig. 4 demonstrates that dexmedetomidine (10$100 \mathrm{ng} \mathrm{ml}^{-1}$ ) increased cGMP levels in a dose-dependent manner in the presence of yohimbine. Rilmenigine $(100 \mu \mathrm{M})$, an $\mathrm{I}_{1}$-agonist, also increased cGMP levels in the presence of yohimbine. The increase in cGMP production induced by both dexmedetomidine and rilmenigine was abolished by efaroxan. These results suggest that dexmedetomidine increases cGMP levels via the $\mathrm{I}_{1}$-receptor, leading to $\mathrm{GC}$ activation and suppression of platelet aggregation. 


\section{Discussion}

In this study, we aimed to elucidate the effect of dexmedetomidine on human platelet functions in vitro. The results demonstrate that dexmedetomidine potentiates and suppresses human platelet function via the $\alpha_{2}$-adrenoceptor and the $\mathrm{I}_{1}$-imidazoine receptor, respectively, as depicted in Fig. 5. This is the first report showing that dexmedetomidine produces a bidirectional effect on human platelet.

Activation of the $\alpha_{2}$-adrenoceptor induces inhibition of adenylate cyclase (AC) and reduction of cAMP formation from adenosine triphosphate (Limbird, 1988). It has been reported that reduction in cAMP levels induces platelet activation by suppressing cAMP-dependent phosphorylation of the inositol trisphosphate receptor and potentiating calcium release from the endoplasmic reticulum (Keularts et al., 2000). The results in this study showed that dexmedetomidine enhanced ADP-induced platelet aggregation and suppressed platelet cAMP formation via the $\alpha_{2}$-adrenoceptor. Together with previous reports, it is suggested that dexmedetomidine activates the $\alpha_{2}$-adrenoceptor leading to suppression of cAMP formation, an increase in cytosolic calcium levels, and finaly enhances platelet activation.

Spontaneous platelet aggregation, generally defined as the formation of small-sized aggregates without any stimulation under constant stirring (Ozaki et al., 1994), could be considered as the initial aggregation step leading to thrombus formation. The spontaneously formed small-sized aggregates of platelets play a pivotal role in cardiovascular events and predict the occurrence of these events more reliably than the change in the agonist-induced aggregation (Kajiwara et al., 2001; Miyamoto et al., 2000). On the other hand, P-selectin, one of 
the adhesion molecules involved in the interaction between platelets and other cells, stabilizes the initial platelet aggregates in human platelets in vitro (Merten and Thiagarajan, 2000), and contributes to the increase and stabilization of arterial thrombi (Christersson et al., 2008; Yokoyama et al., 2005). Clinical studies demonstrated that platelet surface P-selectin expression is increased in the context of arteriosclerosis, ischemic stroke and peripheral arterial disease (Burger and Wagner, 2003; Marquardt et al., 2002; Zeiger et al., 2000). Since our results demonstrated that dexmedetomidine enhances spontaneous aggregation and $\mathrm{P}$-selectin expression, it might be possible that dexmedetomidine enhances thrombus formation particularly in patients with high blood coagulability.

We showed that dexmedetomidine suppressed ADP-induced platelet aggregation via the $\mathrm{I}_{1}$-receptor. The $\mathrm{I}_{1}$-receptor is expressed in platelets, and neural and epithelial cells (Dahmani et al., 2008; Piletz and Sletten, 1993; Piletz et al., 1996; Savola and Savola, 1996; Virtanen et al., 1988; Wikberg et al., 1991), but the physiological functions are not fully understood. Although signal transduction mechanisms activated by the $\mathrm{I}_{1}$-receptor remain to be clarified, we hypothesized that cGMP is involved in the $\mathrm{I}_{1}$-receptor-mediated inhibition of platelet aggregation, because an increase in the intracellular cGMP level can inhibit platelet aggregation (Smolenski, 2012), and clonidine increases cGMP production by the action on the I-receptors in the rat adrenal gland (Regunathan et al., 1990). Our results demonstrated that the suppressive effect of dexmedetomidine on ADP-inducded platelet aggregation was reduced by methylene blue, a GC inhibitor, and that cGMP formation was increased by dexmedetomidine, which was inhibited by efaroxan. Thus, it is suggested that dexmedetomidine suppresses ADP-induced 
platelet aggregation by $\mathrm{I}_{1}$-receptor activation resulting in $\mathrm{GC}$ activation and an increase in cGMP formation. Further study is necessary to elucidate the mechanism of $\mathrm{I}_{1}$-receptor-mediated GC activation.

Although there have been several reports on the effects of dexmedetomidine on bleeding during surgery, the results are not consistent and the mechanism for its effect on bleeding has not been fully explored. Durmus et al. (2007) demonstrated that dexmedetomidine decreased bleeding in patients undergoing elective tympanoplasty and septorhinoplasty under general anesthesia. In contrast, Mizrak et al. (2013) reported that dexmedetomidine increased bleeding in pediatric patients undergoing adenotonsillectomy. Our results demonstrated that dexmedetomidine has both enhancing and suppressive effects on platelet functions, and that a drug with $\alpha_{2}$-antagonist-like activity affects which of the two opposite effects becomes evident. Therefore, the effects of dexmedetomidine on bleeding might depend on whether dexmedetomidine is administered together with drugs blocking the $\alpha_{2}$-adrenoreceptor, such as yohimbine, a selective $\alpha_{2}$-antagonist used for treatment of male sexual dysfunction (Tam et al., 2001), and phenoxybenzamine, a non-selective $\alpha$-antagonist used for perioperative management of pheochromocytoma (Agrawal et al., 2014). The effects of dexmedetomidine on hemostasis might be more apparent in patients whose platelet number in the blood is seriously decreased by a variety of pathophysiological mechanisms. Further studies are necessary to clarify whether dexmedetomidine actually affects platelet functions and hemostasis in the clinical setting.

There are some limitations in this study. The first limitation is that the concentration of dexmedetomidine used in our study was apparently higher than the usual therapeutic 
concentration range (0.4-1.2 $\mathrm{ng} \mathrm{ml}^{-1}$ ) (Venn et al., 2002). In fact, Kose et al. (2013) showed that 0.4-1.2 $\mathrm{ng} \mathrm{ml}^{-1}$ of dexmedetomidine had no effect on platelet aggregation induced by ADP, collagen, and epinephrine in vitro. However, because it was reported that the plasma concentration of dexmedetomidine can reach $10 \mathrm{ng} \mathrm{ml}^{-1}$ in patients with liver dysfunction and the elimination half-life and context-sensitive half-time of dexmedetomidine are prolonged in the elderly and by hypoalbuminemia (Iirola et al., 2012), it might be possible that dexmedetomidine affects platelet functions in the clinical setting. The second limitation is that our study was performed in vitro and could not evaluate the effects of blood flow, blood vessels, shear stress on platelets, and the interactions between platelets and other blood cells. To clarify the involvement of these factors in the effect of dexmedetomidine on hemostasis, an in vivo study is required. The third limitation is that we analyzed the effect of dexmedetomidine on platelet aggregation induced by only ADP. Because we cannot exclude the possibility that the effect of dexmedetomidine is dependent on the type of stimulation, we should examine the effect of dexmedetomidine on platelets stimulated with other agonists including collagen and thrombin in future.

\section{Conclusions}

The present study demonstrated that dexmedetomidine has both enhancing and suppressive effects on platelet functions in vitro. Our data suggest that the enhancing effect is mediated by activation of the $\alpha_{2}$-adrenoceptor and inhibition of AC, while the suppressive effect is mediated by activation of the $\mathrm{I}_{1}$-receptor and GC. 


\section{Authors' Contributions}

S.K.: data collection, data analysis, and drafting of the paper. N.S.: help with data collection and analysis. H.H.: study conception and design, interpretation of data, and revision of the manuscript. K.F.: supervising the study and revision of the manuscript. All authors have approved the final version of the paper.

\section{Declaration of interest}

None declared.

\section{Funding}

This work was supported solely by departmental sources. 


\section{References}

Agrawal, R., Mishra, S.K., Bhatia, E., Mishra, A., Chand, G., Agarwal, G., Agarwal, A., Verma, A.K., 2014. Prospective study to compare peri-operative hemodynamic alterations following preparation for pheochromocytoma surgery by phenoxybenzamine or prazosin. World J Surg 38, 716-723.

Burger, P.C., Wagner, D.D., 2003. Platelet P-selectin facilitates atherosclerotic lesion development. Blood 101, 2661-2666.

Christersson, C., Johnell, M., Siegbahn, A., 2008. Tissue factor and IL8 production by Pselectin-dependent platelet-monocyte aggregates in whole blood involves phosphorylation of Lyn and is inhibited by IL10. J Thromb Haemost 6, 986-994.

Dahmani, S., Paris, A., Jannier, V., Hein, L., Rouelle, D., Scholz, J., Gressens, P., Mantz, J., 2008. Dexmedetomidine increases hippocampal phosphorylated extracellular signalregulated protein kinase 1 and 2 content by an alpha 2-adrenoceptor-independent mechanism: evidence for the involvement of imidazoline I1 receptors. Anesthesiology $108,457-466$.

Durmus, M., But, A.K., Dogan, Z., Yucel, A., Miman, M.C., Ersoy, M.O., 2007. Effect of dexmedetomidine on bleeding during tympanoplasty or septorhinoplasty. Eur J Anaesthesiol 24, 447-453.

Ernsberger, P., Friedman, J.E., Koletsky, R.J., 1997a. The I1-imidazoline receptor: from binding site to therapeutic target in cardiovascular disease. J Hypertens Suppl 15, S9-23. 
Ernsberger, P., Haxhiu, M.A., 1997b. The I1-imidazoline-binding site is a functional receptor mediating vasodepression via the ventral medulla. Am J Physiol 273, R1572-1579.

Furie, B., Furie, B.C., Flaumenhaft, R., 2001. A journey with platelet P-selectin: the molecular basis of granule secretion, signalling and cell adhesion. Thromb Haemost 86, 214-221.

Hirakata, H., Nakamura, K., Sai, S., Okuda, H., Hatano, Y., Urabe, N., Mori, K., 1997. Platelet aggregation is impaired during anaesthesia with sevoflurane but not with isoflurane. Can J Anaesth 44, 1157-1161.

Hirakata, H., Nakamura, K., Yokubol, B., Toda, H., Hatano, Y., Urabe, N., Mori, K., 1999. Propofol has both enhancing and suppressing effects on human platelet aggregation in vitro. Anesthesiology 91, 1361-1369.

Hirakata, H., Ushikubi, F., Narumiya, S., Hatano, Y., Nakamura, K., Mori, K., 1995. The effect of inhaled anesthetics on the platelet aggregation and the ligand-binding affinity of the platelet thromboxane A2 receptor. Anesth Analg 81, 114-118.

Hirakata, H., Ushikubi, F., Toda, H., Nakamura, K., Sai, S., Urabe, N., Hatano, Y., Narumiya, S., Mori, K., 1996. Sevoflurane inhibits human platelet aggregation and thromboxane A2 formation, possibly by suppression of cyclooxygenase activity. Anesthesiology $85,1447-$ 1453.

Iirola, T., Ihmsen, H., Laitio, R., Kentala, E., Aantaa, R., Kurvinen, J.P., Scheinin, M., Schwilden, H., Schuttler, J., Olkkola, K.T., 2012. Population pharmacokinetics of dexmedetomidine during long-term sedation in intensive care patients. Br J Anaesth 108, 460-468. 
Jansson, C.C., Marjamaki, A., Luomala, K., Savola, J.M., Scheinin, M., Akerman, K.E., 1994. Coupling of human alpha 2-adrenoceptor subtypes to regulation of cAMP production in transfected S115 cells. Eur J Pharmacol 266, 165-174.

Kajiwara, I., Ogawa, H., Soejima, H., Takazoe, K., Miyamoto, S., Sakamoto, T., Yoshimura, M., Kugiyama, K., Yasue, H., 2001. The prognostic value of small-sized platelet aggregates in unstable angina: detection by a novel laser-light scattering method. Thromb Res 101, 109-118.

Kamibayashi, T., Maze, M., 2000. Clinical uses of alpha2 -adrenergic agonists. Anesthesiology 93, 1345-1349.

Keularts, I.M., van Gorp, R.M., Feijge, M.A., Vuist, W.M., Heemskerk, J.W., 2000. alpha(2A)adrenergic receptor stimulation potentiates calcium release in platelets by modulating cAMP levels. J Biol Chem 275, 1763-1772.

Kose, E.A., Nevruz, O., Honca, M., Yildirim, V., 2013. In vitro effect of dexmedetomidine on platelet aggregation. Braz J Anesthesiol 63, 415-418.

Lanza, F., Cazenave, J.P., 1985. Studies of alpha 2-adrenergic receptors of intact and functional washed human platelets by binding of 3H-dihydroergocryptine and 3H-yohimbine-correlation of $3 \mathrm{H}$-yohimbine binding with the potentiation by adrenaline of ADP-induced aggregation. Thromb Haemost 54, 402-408.

Limbird, L.E., 1988. Receptors linked to inhibition of adenylate cyclase: additional signaling mechanisms. FASEB J 2, 2686-2695. 
Marquardt, L., Ruf, A., Mansmann, U., Winter, R., Schuler, M., Buggle, F., Mayer, H., Grau, A.J., 2002. Course of platelet activation markers after ischemic stroke. Stroke 33, 25702574.

Merten, M., Thiagarajan, P., 2000. P-selectin expression on platelets determines size and stability of platelet aggregates. Circulation 102, 1931-1936.

Michel, M.C., Regan, J.W., Gerhardt, M.A., Neubig, R.R., Insel, P.A., Motulsky, H.J., 1990. Nonadrenergic $[3 \mathrm{H}]$ idazoxan binding sites are physically distinct from alpha 2 -adrenergic receptors. Mol Pharmacol 37, 65-68.

Miyamoto, S., Ogawa, H., Soejima, H., Takazoe, K., Kajiwara, I., Sakamoto, T., Yoshimura, M., Kugiyama, K., Yasue, H., 2000. Increased rate of formation of small-sized platelet aggregates in patients with acute coronary syndromes. Jpn Circ J 64, 647-652.

Mizrak, A., Karatas, E., Saruhan, R., Kara, F., Oner, U., Saricicek, V., Baysal, E., 2013. Does dexmedetomidine affect intraoperative blood loss and clotting tests in pediatric adenotonsillectomy patients? J Surg Res 179, 94-98.

Nakagawa, T., Hirakata, H., Sato, M., Nakamura, K., Hatano, Y., Nakamura, T., Fukuda, K., 2002. Ketamine suppresses platelet aggregation possibly by suppressed inositol triphosphate formation and subsequent suppression of cytosolic calcium increase. Anesthesiology 96, 1147-1152.

Ozaki, Y., Satoh, K., Yatomi, Y., Yamamoto, T., Shirasawa, Y., Kume, S., 1994. Detection of platelet aggregates with a particle counting method using light scattering. Anal Biochem 218, 284-294. 
Piletz, J.E., Sletten, K., 1993. Nonadrenergic imidazoline binding sites on human platelets. J Pharmacol Exp Ther 267, 1493-1502.

Piletz, J.E., Zhu, H., Chikkala, D.N., 1996. Comparison of ligand binding affinities at human I1imidazoline binding sites and the high affinity state of alpha-2 adrenoceptor subtypes. J Pharmacol Exp Ther 279, 694-702.

Ramsay, M.A., Luterman, D.L., 2004. Dexmedetomidine as a total intravenous anesthetic agent. Anesthesiology 101, 787-790.

Regunathan, S., Meeley, M.P., Reis, D.J., 1990. Effect of clonidine on second messenger systems in rat adrenal gland. Life Sci 47, 2127-2133.

Savola, M.K., Savola, J.M., 1996. [3H]dexmedetomidine, an alpha 2-adrenoceptor agonist, detects a novel imidazole binding site in adult rat spinal cord. Eur J Pharmacol 306, 315323.

Smolenski, A., 2012. Novel roles of cAMP/cGMP-dependent signaling in platelets. J Thromb Haemost 10, 167-176.

Tam, S.W., Worcel, M., Wyllie, M., 2001. Yohimbine: a clinical review. Pharmacol Ther 91, 215-243.

Venn, R.M., Karol, M.D., Grounds, R.M., 2002. Pharmacokinetics of dexmedetomidine infusions for sedation of postoperative patients requiring intensive caret. Br J Anaesth 88, $669-675$. 
Virtanen, R., Savola, J.M., Saano, V., Nyman, L., 1988. Characterization of the selectivity, specificity and potency of medetomidine as an alpha 2-adrenoceptor agonist. Eur J Pharmacol 150, 9-14.

Wikberg, J.E., Uhlen, S., Chhajlani, V., 1991. Medetomidine stereoisomers delineate two closely related subtypes of idazoxan (imidazoline) I-receptors in the guinea pig. Eur J Pharmacol 193, 335-340.

Yokota, S., Hikasa, Y., Mizushima, H., 2013. Effects of imidazoline and non-imidazoline alphaadrenergic agents on rabbit platelet aggregation. Pharmacology 91, 135-144.

Yokoyama, S., Ikeda, H., Haramaki, N., Yasukawa, H., Murohara, T., Imaizumi, T., 2005. Platelet P-selectin plays an important role in arterial thrombogenesis by forming large stable platelet-leukocyte aggregates. J Am Coll Cardiol 45, 1280-1286.

Zeiger, F., Stephan, S., Hoheisel, G., Pfeiffer, D., Ruehlmann, C., Koksch, M., 2000. P-Selectin expression, platelet aggregates, and platelet-derived microparticle formation are increased in peripheral arterial disease. Blood Coagul Fibrinolysis 11, 723-728. 
Figure legends

Fig. 1. Effects of dexmedetomidine on human platelet aggregation. (A) Effects of dexmedetomidine (DEX; 1-500 $\mathrm{ng} \mathrm{ml}^{-1}$ ) and levomedetomidine (LEVO; $500 \mathrm{ng} \mathrm{ml}^{-1}$ ) on platelet aggregation induced by $0.5 \mu \mathrm{M}$ ADP. The data are expressed as mean $\pm \mathrm{SD}(\mathrm{n}=5) .{ }^{*} P<0.05$ vs. $\mathrm{DEX}(-)$, LEVO (-). (B) Effects of dexmedetomidine (DEX; $10 \mathrm{ng} \mathrm{ml}^{-1}$ ) on platelet aggregation induced by $1.5 \mu \mathrm{M}$ ADP in the presence and absence of yohimbine $(\mathrm{YH} ; 10 \mu \mathrm{M})$, efaroxan $(\mathrm{EX} ; 10 \mu \mathrm{M})$, idazoxan $(\mathrm{IX} ; 10 \mu \mathrm{M})$, and methylene blue $(\mathrm{MB} ; 3 \mu \mathrm{M})$. The data are expressed as mean $\pm \mathrm{SD}(\mathrm{n}=$ 5). ${ }^{*} P<0.05$ vs. DEX (-), YH (-), EX(-), IX (-), MB (-). (C) Effects of dexmedetomidine (DEX; 1$10 \mathrm{ng} \mathrm{ml}^{-1}$ ) and levomedetomidine (LEVO; $100 \mathrm{ng} \mathrm{ml}^{-1}$ ) on spontaneous platelet aggregation in the absence and presence of yohimbine $(\mathrm{YH} ; 10 \mu \mathrm{M})$. The data are expressed as mean $\pm \mathrm{SD}(\mathrm{n}=$ 5). ${ }^{*} P<0.05$ vs. DEX (-), YH (-), LEVO (-). Dexmedetomidine enhanced both ADP-induced and spontaneous platelet aggregation, whereas levomedetomidine showed no effect on platelt aggregation. Dexmedetomidine suppressed ADP-induced platelet aggregation in the presence of yohimbine, and this effect was abolished by efaroxan and methylene blue.

Fig. 2. Effects of dexmedetomidine (DEX; $10 \mathrm{ng} \mathrm{ml}^{-1}$ ) (A) and levomedetomidine (LEVO; 100 $\mathrm{ng} \mathrm{ml}^{-1}$ ) (B) on cAMP formation in platelets stimulated with $0.1 \mu \mathrm{M} 9,11$-epithio-11, 12 methanothromboxane $\mathrm{A}_{2}\left(\mathrm{STA}_{2}\right)$ for $7 \mathrm{~min}$ in the presence and absence of yohimbine $(\mathrm{YH} ; 100$ $\mu \mathrm{M})$. The data are expressed as mean $\pm \mathrm{SD}(\mathrm{n}=3) . * P<0.05$ vs. $\mathrm{DEX}(-), \mathrm{YH}(-)$.

Dexmedetomidine suppressed cAMP formation, and this effect was blocked by yohimbine, 
whereas levomedetomidine did not significantly affect cAMP formation in the presence or absence of yohimbine.

Fig. 3. Effect of dexmedetomidine (DEX; 1-100 $\mathrm{ng} \mathrm{ml}^{-1}$ ) and levomedetomidine (LEVO; $100 \mathrm{ng}$ $\mathrm{ml}^{-1}$ ) on surface P-selectin expression in platelets. Experiments were performed with (A) or without (B) stimulation by $10 \mu \mathrm{M}$ ADP in the presence and absence of yohimbine (YH; $10 \mu \mathrm{M})$. MFI, mean fluorescence intensity. The data are expressed as mean $\pm \mathrm{SD}(\mathrm{n}=4)$. ${ }^{*} P<0.05$ vs. DEX (-), YH (-), LEVO (-). In the presence or absence of ADP stimulation, dexmedetomidine enhanced P-selectin expression in a yohimbine-sensitive manner, whereas levomedetomidine did not significantly affect P-selectin expression.

Fig. 4. Effect of dexmedetomidine (DEX; $1-100 \mathrm{ng} \mathrm{ml}^{-1}$ ) and rilmenigine (RLM; $\left.100 \mu \mathrm{M}\right)$ on cGMP formation in the presence of yohimbine $(\mathrm{YH} ; 100 \mu \mathrm{M})$. Efaroxan $(\mathrm{EX} ; 10 \mu \mathrm{M})$ abolished the enhancing effect of dexmedetomidine and rilmenigine. The data are expressed as mean \pm SD $(\mathrm{n}=5) .{ }^{*} P<0.05$ vs. $\operatorname{DEX}(-), \operatorname{RLM}(-), \operatorname{EX}(-)$.

Fig. 5. Bidirectional effects of dexmedetomidine (DEX) on platelet aggregation. DEX activates the $\alpha_{2}$-adrenoceptor $\left(\alpha_{2} R\right)$, leading to suppression of adenylate cyclase and cAMP formation, and finaly enhances platelet aggregation. On the other hand, DEX activates guanylate cyclase and increases cGMP levels via the $\mathrm{I}_{1}$-imidazoline receptor $\left(\mathrm{I}_{1} \mathrm{R}\right)$, leading to suppression of platelet 
aggregation. White and black arrows represent the DEX-induced effects involvong $\alpha_{2} R$ and $I_{1} R$, respectively. Upward and downward arrows show activation/increase and inhibition/decrease, respectively. The interrupted lines represent the effects of the inhibitors used in this study. Yohimbine and efaroxan inhibit the DEX-induced $\alpha_{2}$ - and $\mathrm{I}_{1}$-activation, respectively. Methylene blue suppresses guanylate cyclase activity. The dotted line represens the action of rilmenigine, which activates $\mathrm{I}_{1} \mathrm{R}$ leading to increase in cGMP. ATP; adenosine triphosphate, GTP; guanosine triphosphate, cAMP; cyclic adenosine monophosphate, cGMP; cyclic guanosine monophosphate. 
Professor F.P. Nijkamp,

Editor-in-Chief, European Journal of Pharmacology.

Dear Dr. Nijkamp:

On behalf of my co-authors, I would like to ask you to consider our manuscript entitled "Bidirectional effects of dexmedetomidine on human platelet functions in vitro" for publication in the European Journal of Pharmacology as an original research report.

Because platelets are essential for keeping hemostasis, information on the effects of perioperatively used drugs including anesthetics on platelet functions is indispensable for perioperative patient care. This is the first report showing both enhancing and suppressive effects of dexmedetomidine on human platelet functions in vitro. Our results suggest that the enhancing effect is mediated by activation of the $\alpha_{2}$-adrenoceptor and inhibition of adenylate cyclase, while the suppressive effect is mediated by activation of the imidazoline $\mathrm{I}_{1}$-receptor and guanylate cyclase. Because dexmedetomidine is frequently used for sedation and analgesia for critically ill patients, our results would provide useful information for intensive care. We feel that the findings from this study will be of particular interest to the readers of the European Journal of Pharmacology.

This manuscript has not been published and is not under consideration for publication elsewhere. All the authors have read the manuscript and have approved this submission. Financial support for this study was provided solely by departmental funds. The authors report no conflicts of interest.

I hope you find our manuscript worthy of publication in the European Journal of Pharmacology. I am looking forward to hearing from you.

Sincerely,

Shuji Kawamoto M.D.

Department of Anesthesia, Kyoto University Hospital

54 Shogoin Kawahara-cho, Sakyo-ku, Kyoto 606-8507, Japan.

TEL: +81-75-751-3433; FAX: +81-75-752-3259; e-mail: shuji-kawamoto@ares.eonet.ne.jp 


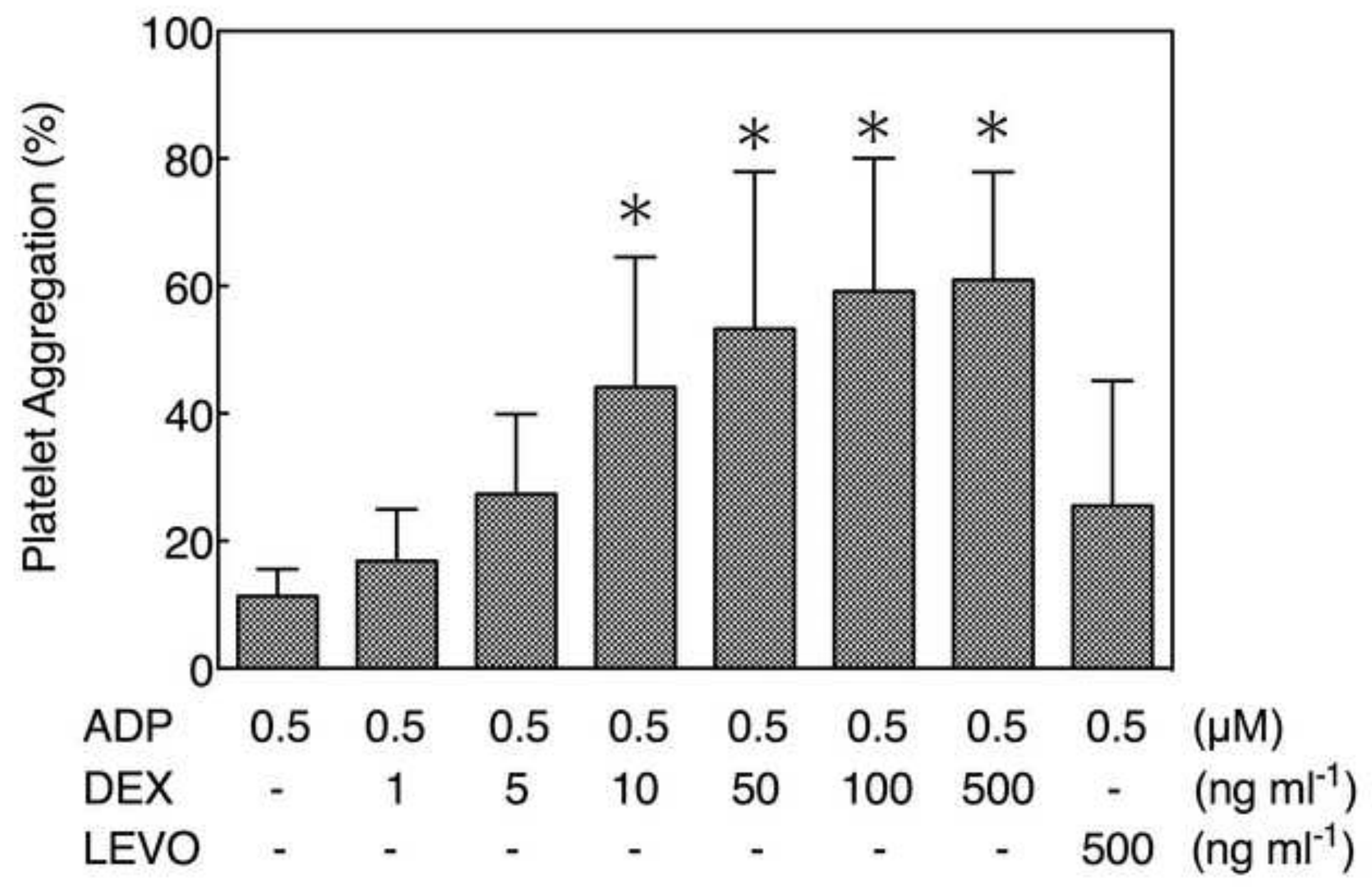

Fig. 1A 


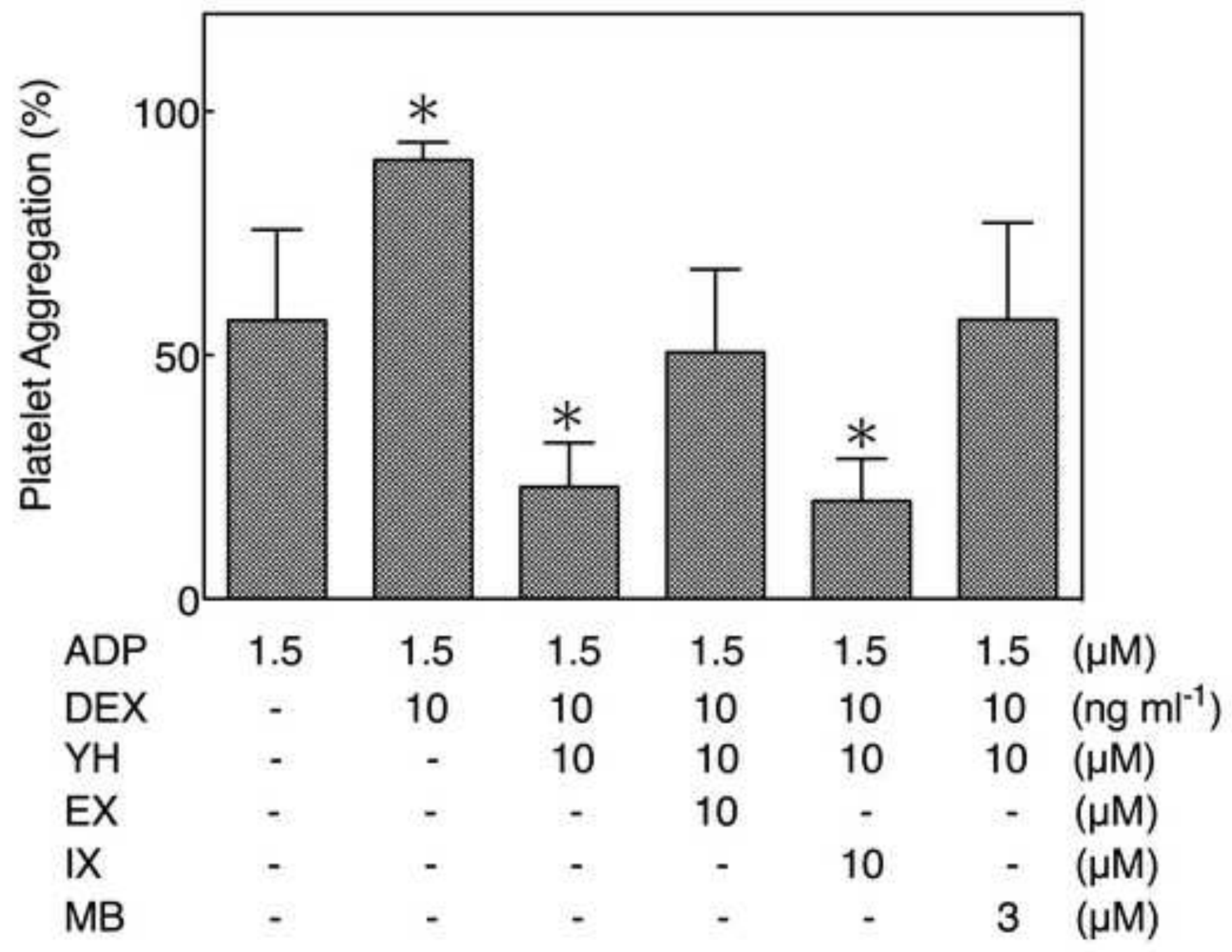

Fig. 1B 


\section{Figure10}

Click here to download high resolution image

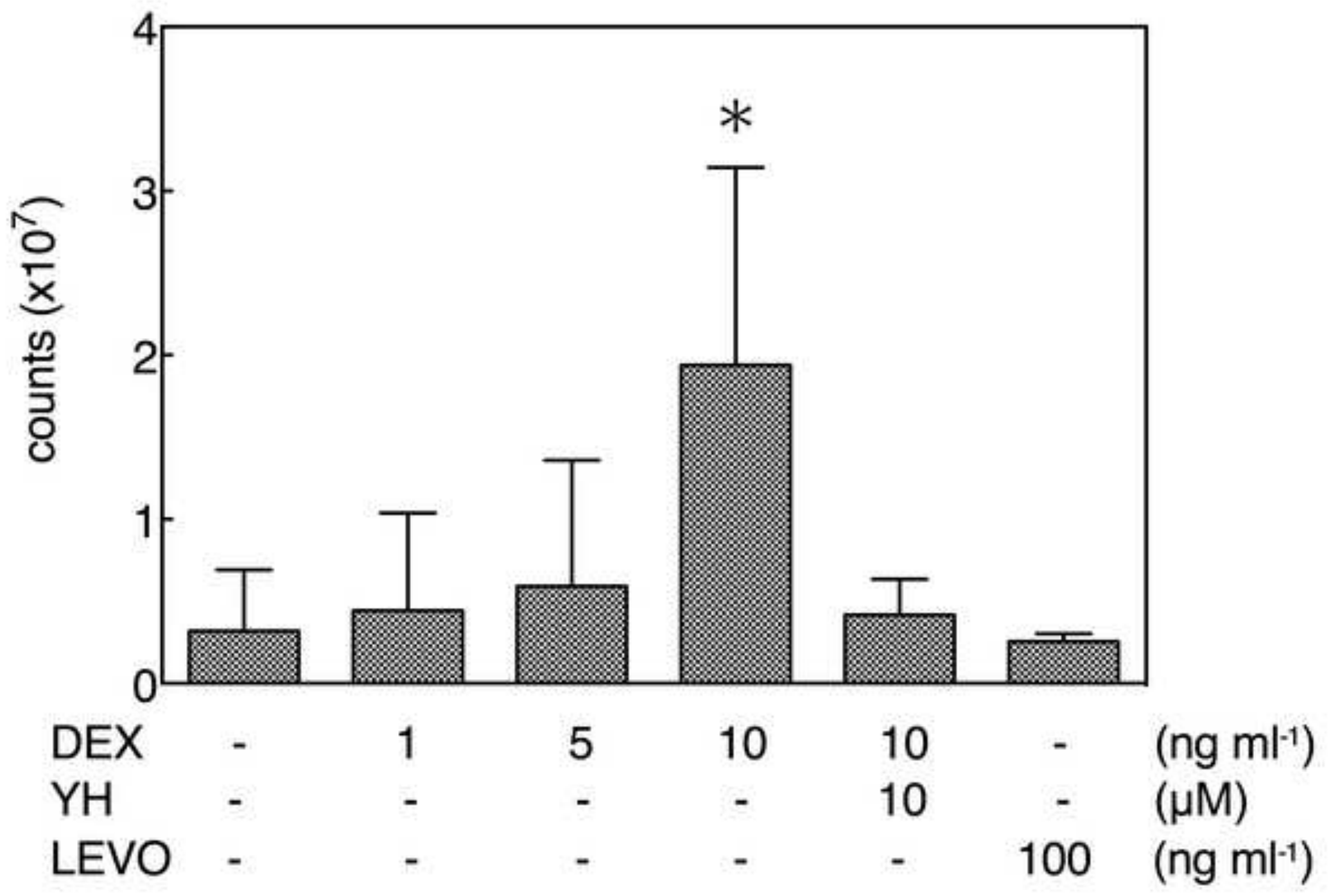

Fig. 1C 
A

B
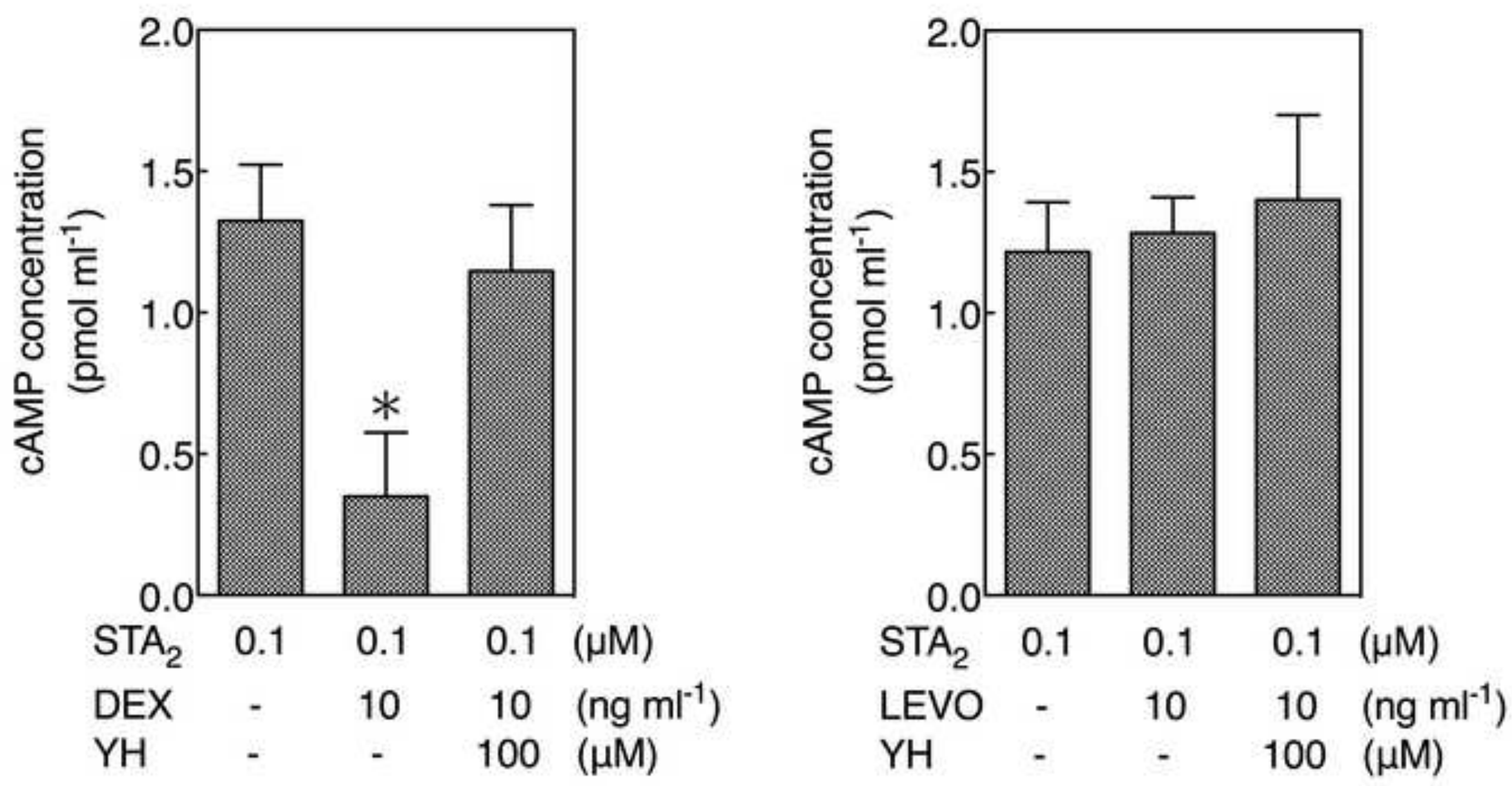

Fig. 2 
A

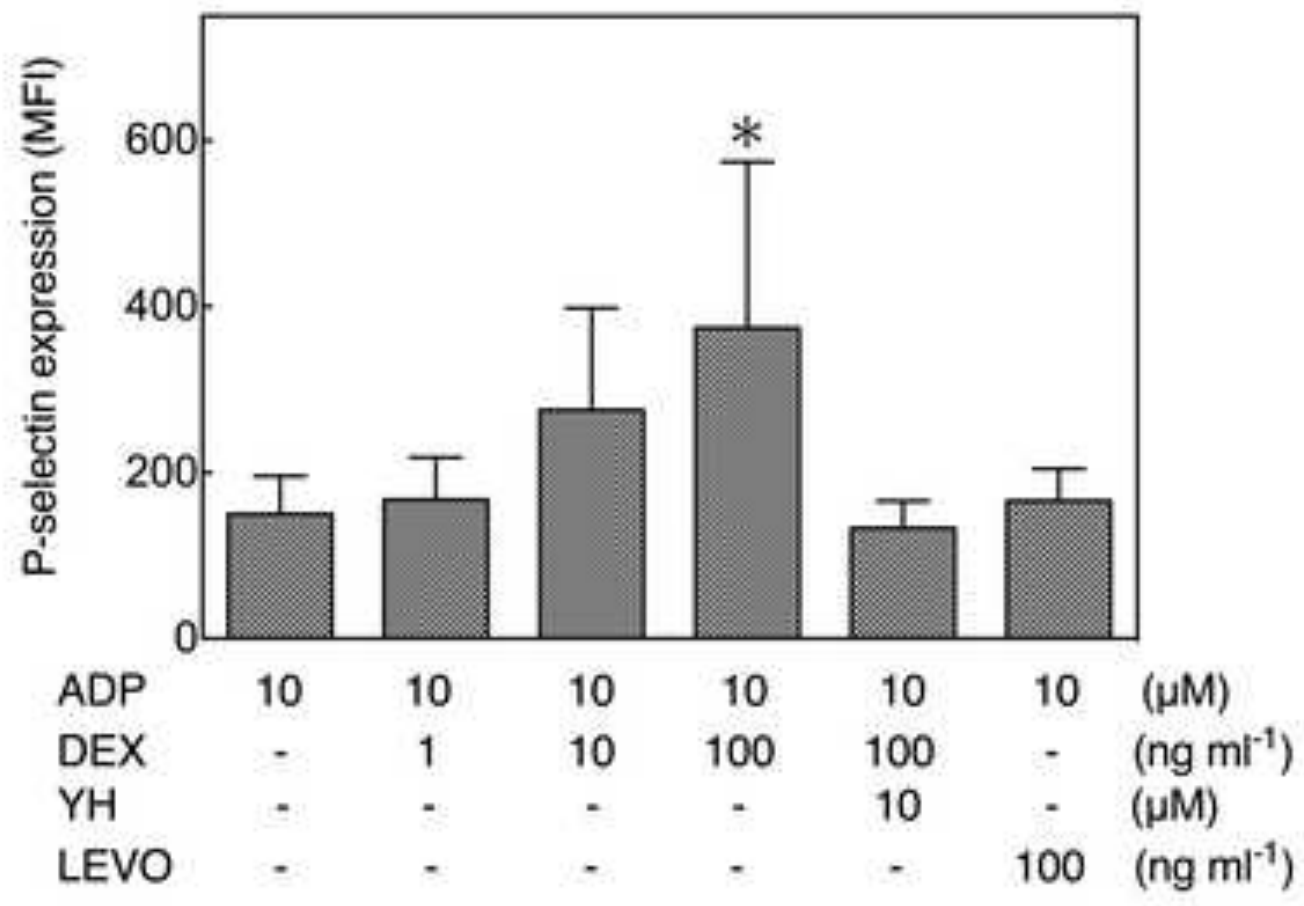

B

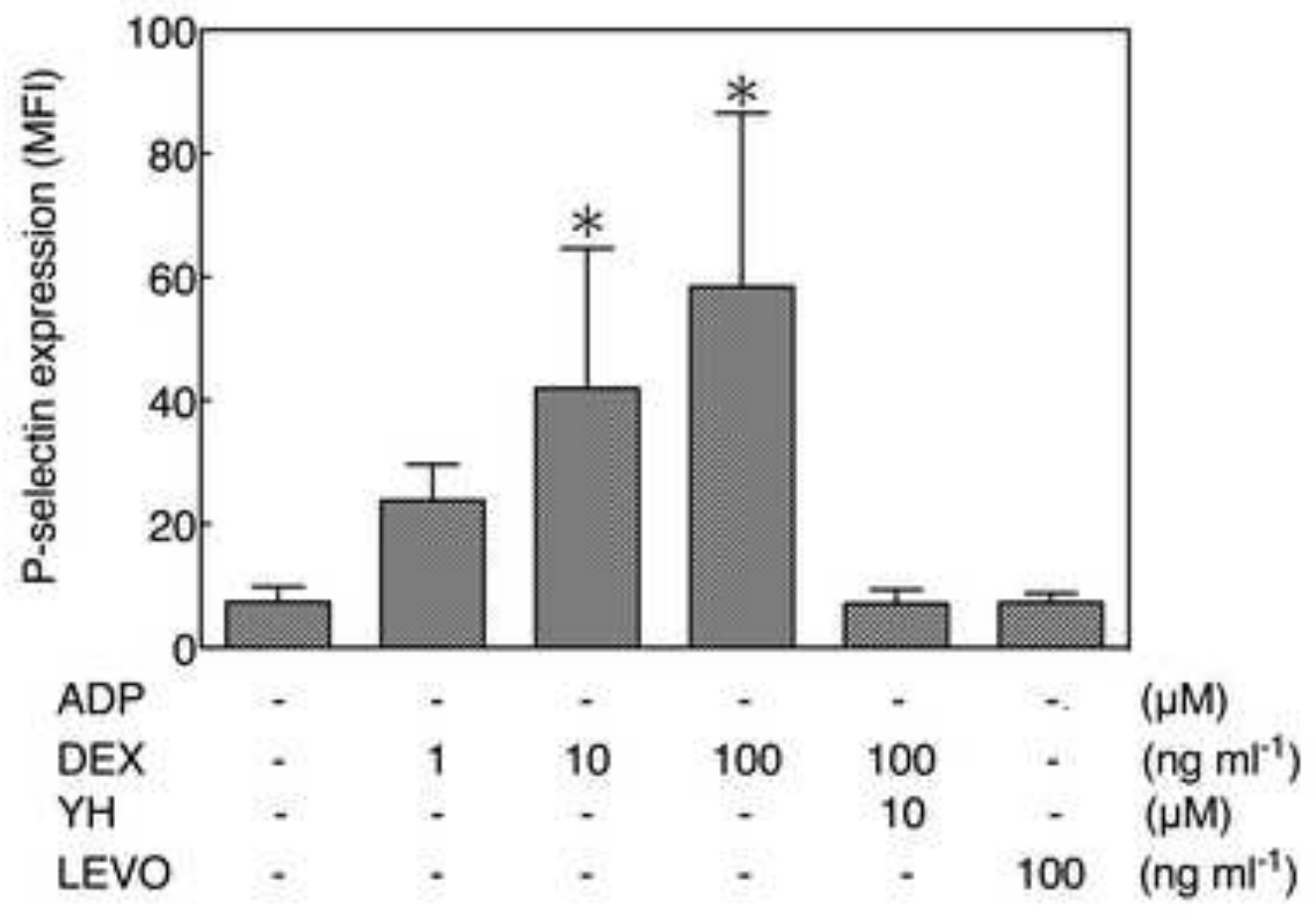

Fig. 3 


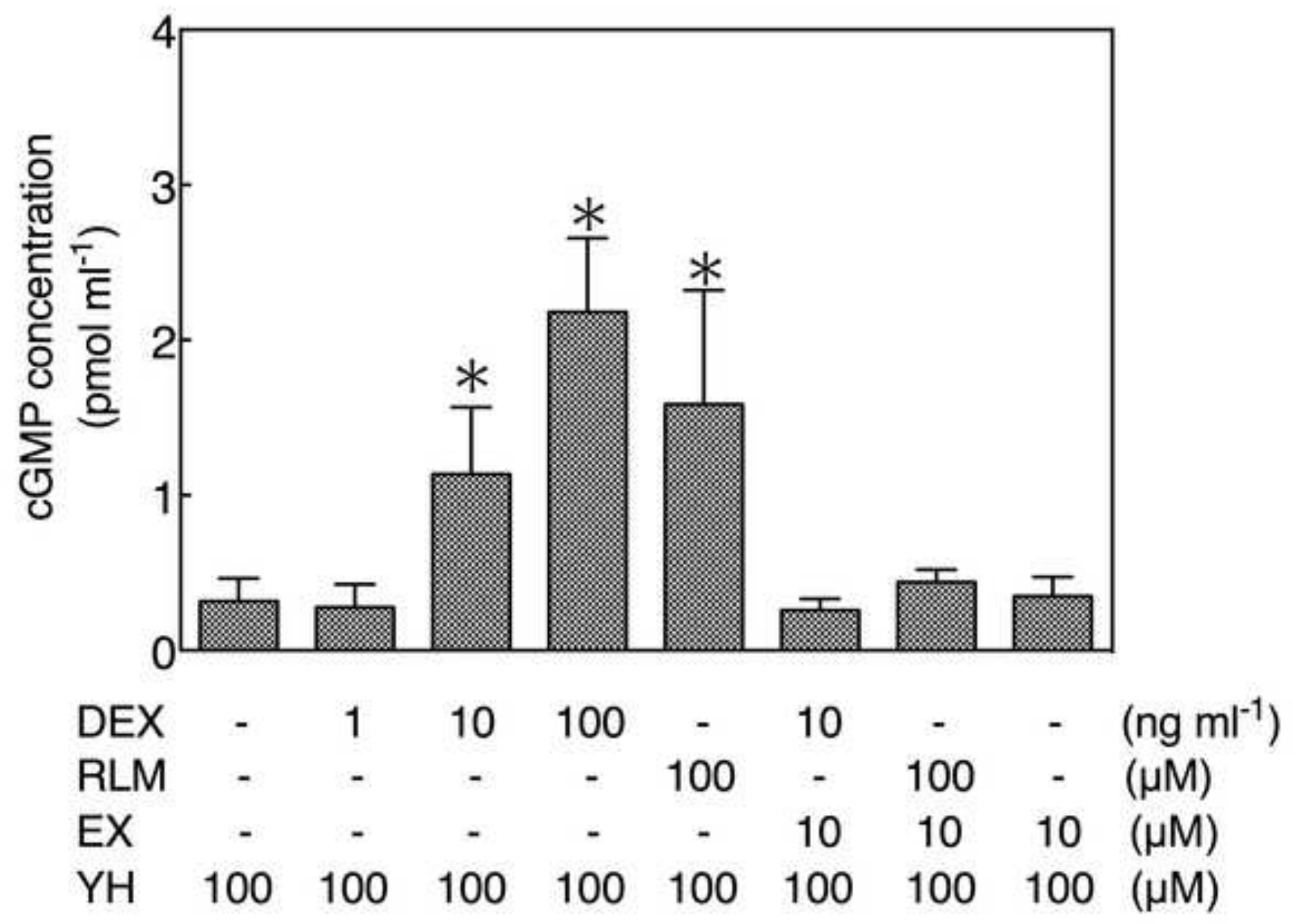

Fig. 4 


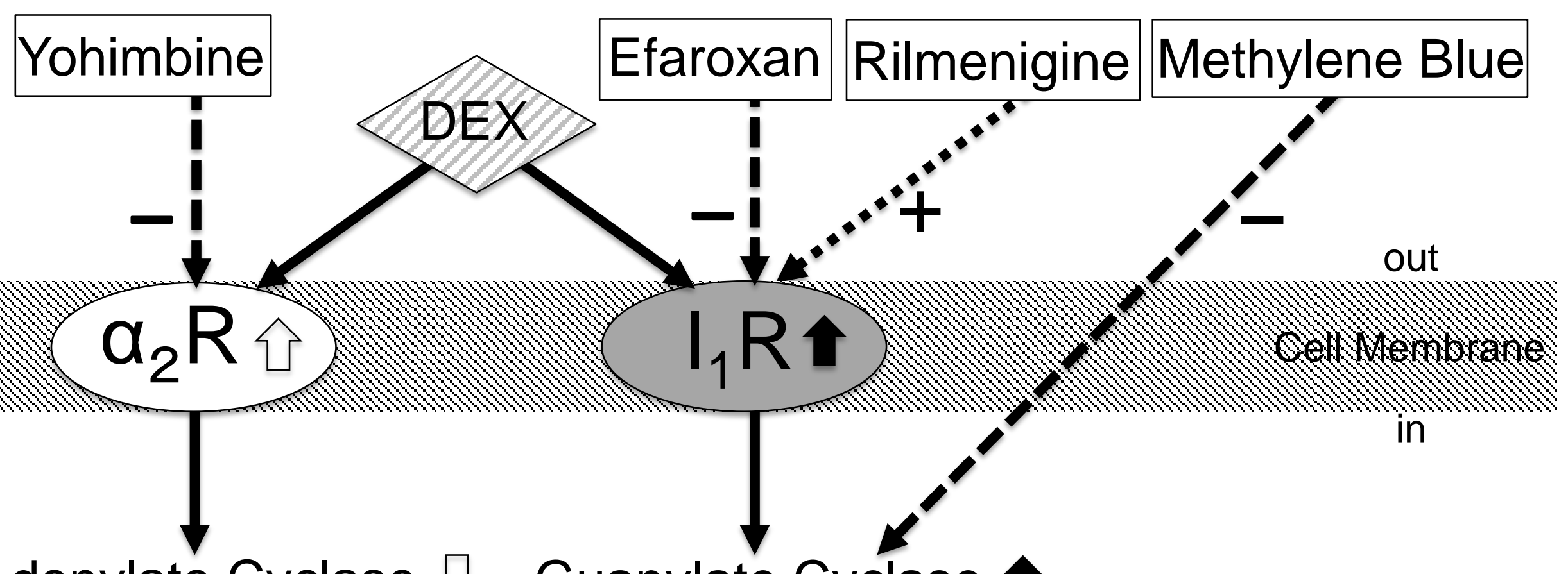

Adenylate Cyclase $\diamond \quad$ Guanylate Cyclase

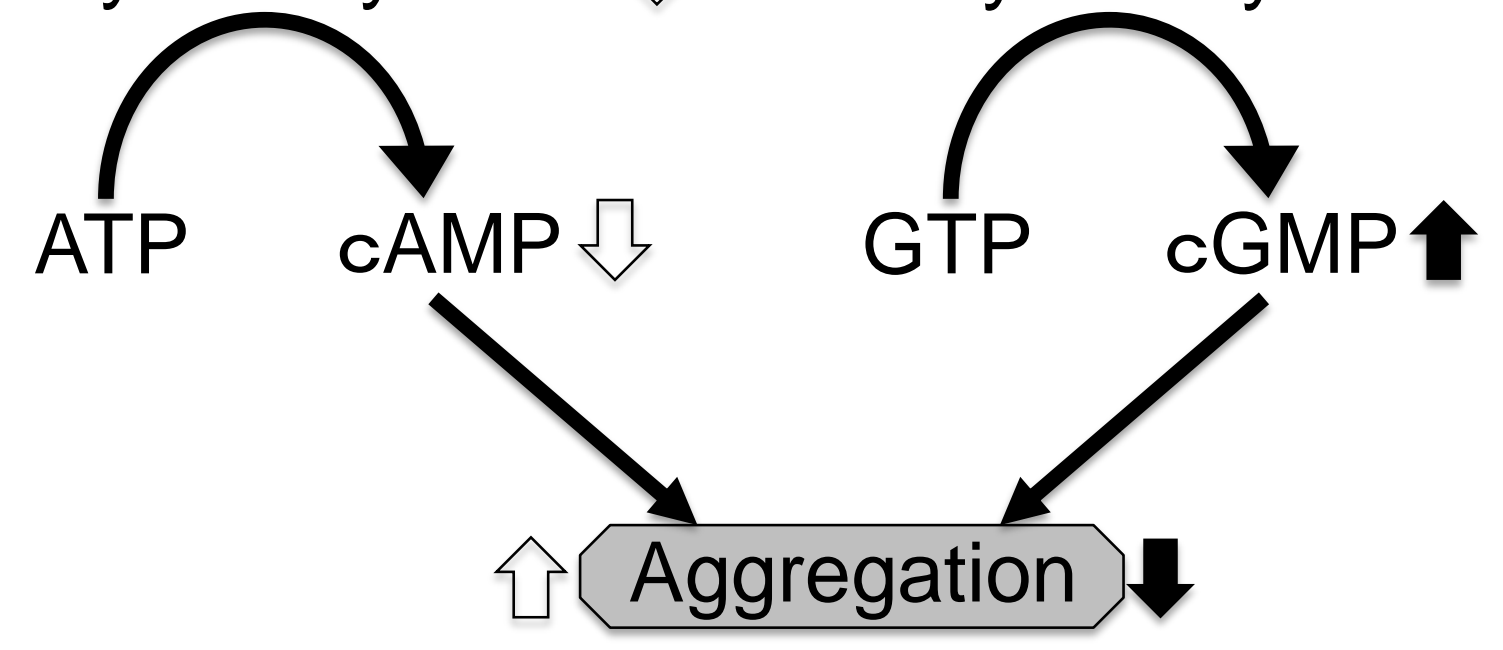

